\title{
Vorwort zur vierten Auflage
}

Ebenso wie die dritte Auflage soll auch die vierte Auflage das gesamte öffentliche und private Seerecht umfassen. Doch ist eine Umstellung erfolgt. Das Seerechtsänderungsgesetz sowie Veränderungen im Seetransport machten vor allem eine Neubearbeitung des Vierten Buchs des Handelsgesetzbuchs erforderlich, zumal auch dessen Bestimmungen für die am Seehandel interessierten Kreise von besonderer Bedeutung sind. Dem Seehandelsrecht ist in dem hier vorgelegten ersten Bande nur die Allgemeine Einleitung vorangestellt. Ein zweiter Band, der etwa den Inhalt des ersten und dritten Bandes der dritten Auflage enthalten soll, vornehmlich also das Seevölkerrecht, das sonstige öffentliche Seerecht, das Flaggen- und Registerrecht, das Seearbeitsrecht und die verkehrs- und hafenrechtlichen Bestimmungen, ist in Aussicht genommen.

Das Manuskript ist im November 1976 abgeschlossen worden. Im Nachtrag 1 finden sich Ergänzungen wesentlicher Art bis zum 31. März 1977. Das Inkrafttreten der Visby-Rules für eine bestimmte Gruppe von Staaten wird in einem weiteren Nachtrag (Nachtrag 2) behandelt.

Bad Homburg v. d. H., im September 1977

Hans Jürgen Abraham 